\title{
Personality Traits and Performance: The Mediating Role of Adaptive Behavior in Call Centers
}

\author{
Said Echchakoui \\ Department of Management, University of Quebec in Abitibi-Témiscamingue, Rouyn-Noranda (QC), Canada. \\ Email: said.echchakoui@uqat.ca
}

Received September $4^{\text {th }}, 2012$; revised October $6^{\text {th }}, 2012$; accepted November $9^{\text {th }}, 2012$

\begin{abstract}
Personality traits and adaptive behavior are central issues in research on call center performance. However, the current literature offers little guidance on the relationship between personality traits and adaptive behavior and how they work together to enhance employee performance. This study investigates the mediating role of adaptive behavior between Five-Factor traits and employee performance with customers. Empirical evidence from a Canadian call center supports this proposition for three Five-Factor traits. Managerial implications are discussed.
\end{abstract}

Keywords: Five-Factor Traits; Adaptive Behavior; Performance with Customers; Call Center; Employee

\section{Introduction}

Call center employees represent the main point of customer contact; therefore, their performance with customers is critical for a call center's success. In light of this, it is important to understand the factors that explain and predict effective employee performance in the call center industry. Personality traits are a critical factor of employee performance. Many call centers, especially in Canada, take personality traits into account in the hiring process. Researchers have found that when selective hiring methods are used, there is less employee turnover, and training efforts are more effective [1,2].

Employee turnover in Canadian call centers is approximately $29 \%$. This success indicates that focusing on the right personality traits in selecting employees is critical for Canadian call centers to maintain a competetive advantage.

Despite the fact that many studies have been conducted in both marketing literature and psychology to assess the relationship between personality traits and performance, data about this relationship in the call center environment is limited. However, primary studies and meta-analyses have shown that under certain conditions, there are relationships between personality traits and call center performance dimensions (e.g., [3-6]). These studies suggest that personality traits explain only a fraction of variance in employee performance (only for $4 \%$ in Churchill et al. [7] meta-analysis). Because of this, many authors (e.g., [8-12]) call for further investigation on the indirect relationship, via moderators or mediating variables, between personality traits and employee perform- ance.

Because market research shows that employee performance is related to adaptive behavior [13,14], significant attention in research and practice has recently been devoted to adaptive behavior in face-to-face environments. However, despite the prominence of adaptive behavior techniques in telephone sales environments [15], there have only been a few studies that have investigated the importance of adaptive behavior in call center contexts [15]. In fact, little is known about the relationship between personality traits, performance and adaptive behavior in call centers.

The purpose of this study is to explore the relationship between personality traits, performance and adaptive behavior in call centers. By addressing this issue, our research makes three contributions. First, our hierarchical model better explains the relationship variance between personality traits and performance in call centers. Second, we have raised questions about and have discovered the need to confirm the qualitative findings of Eveleth and Morris's [15] call center research. Although adaptive behavior has been investigated in other environments [14], we expected that the characteristics of a call center selling environment would require adaptive behavior even more than it would in a face-to-face sales environment. Finally, understanding the characteristics of effective employee is critical for call center competitiveness.

This article is divided into five sections. In the second and third sections, we discuss the theoretical background, address key constructs and present our research model and hypotheses. Data collection methods and analysis 
techniques are explained in the fourth section. In the fifth and sixth sections, we present the results and discuss our findings. The paper concludes with managerial implications, limitations and future research.

\section{Theoretical Background}

\subsection{Personality Traits}

Employee personality can be analyzed in terms of levels of consistency in modes of cognition, affect and behavior [16]. Among personality trait models introduced in the literature, the Big Five model developed by Costa and McCrae [17] has emerged as a popular tool for understanding the relationship between personality and various individual behaviors [18]. It has been employed by many researchers (e.g., [19-22]). The so-called "five factors" are conscientiousness, agreeableness, extraversion, emotional stability and openness to experience. The conscientiousness character of a person indicates the capacity to be responsible, achievement-striving, dependable, efficient, organized, hardworking and persevering. Agreeableness refers the tendency to be sympathetic, helpful, friendly, tolerant, trusting, good-natured, courteous and cooperative. An extraverted person is understood to be ambitious, reward-seeking, gregarious, sociable, adventurous and assertive. Emotional stability refers to the ability to remain calm, resilient, even-tempered, tolerant of stress, well-adjusted and self-confident. Finally, openness to experience indicates the capacity of a person to be broad-minded, imaginative, perceptive, intelligent, creative, curious and cultured.

\subsection{Adaptive Behavior in Call Center Environments}

Adaptive selling is defined as "the altering of sales behavior during a customer interaction or across customer interactions based on perceived information about the nature of the selling situation." Weitz et al. [43]. In other words, to practice adaptive selling a salesperson must change or adapt his selling strategies for each customer. The Weitz et al. (1986) adaptive framework posits that an adaptive selling strategy is critical to the employee's performance in face-to-face interactions. The concept of "adaptation" is also used by researchers in the context of service. Hartline and Ferrell [23] define it as the ability of employees in contact with customers to adjust their behavior according to the application context of clients.

In a call center environment, each employee is located within an individual cubicle and receives several heterogeneous customer calls on a given work day. In contrast to the employee who works in a B-to-B market, employee in call centers interact with customers via phone technology, with calls received through a computer system. In a call center, communication is limited to verbal interaction, thus it is critical for employee to have selling strategies to suit the needs of each customer [15]. Qualitative research conducted by Eveleth and Morris [15] in call centers shows that many employees claim that adaptive behavior significantly affects their work effectiveness.

\subsection{Performance with Customers}

Define Sales performance can be defined as "behavior evaluated in terms of its contribution to the goals of the organization" (Johnston and Marshall [24], p. 412). In the literature, many criteria or types of sales performance have been used (e.g., supervisory rating performance, profit, sales and performance with customers). In our research, we have used performance with customers as the criteria of performance for four reasons. First, Hunter and Perreault $[25,26]$ highlight that performance with customers is a good criterion of performance for a technological organization. They define performance with customers "as developing an understanding of a customer's unique problems and concerns-marketing, technology, operations, or otherwise-and recommending solutions that address those concerns" Hunter and Perreault ([25], p. 99). This definition fits with a call center environment where employees must understand each unique customer's need or objection and be able to provide a personalized solution. In addition, many call centers in Canada deal mainly with phone and Internet companies. Hunter and Perreault's [25,26] definition of performance with customers and the context in which they recommend it is appropriate for call centers in Canada. Second, some researchers (e.g., $[3,4,6]$ ) have highlighted the idea that the relationship between some Five-Factor traits (e.g., agreeableness) and performance depends on performance criteria. Therefore, we think Sawyerr et al.'s [22] call center study result, which found that only one trait of the Five-Factor model is associated with performance, is due mainly to the type of performance studied. Sawyerr et al. [22] have used service performance ratings composed of three items, accuracy of information provided to customers, speed of response to customer requests and the ability to solve problems. Finally, Hunter and Perreault [25] have shown that some Five-Factor traits have been significantly associated with employee performance with customers.

\section{Research Model and Hypotheses}

This study proposes a model that investigates the effects of Five-Factor traits on employee performance with customers at call centers. Specifically, Figure 1 hypothesizes that Five-Factor traits (Conscientiousness, Agreeableness, Extraversion, Emotional Stability and Openness to Experience) directly affect the employee's performance 


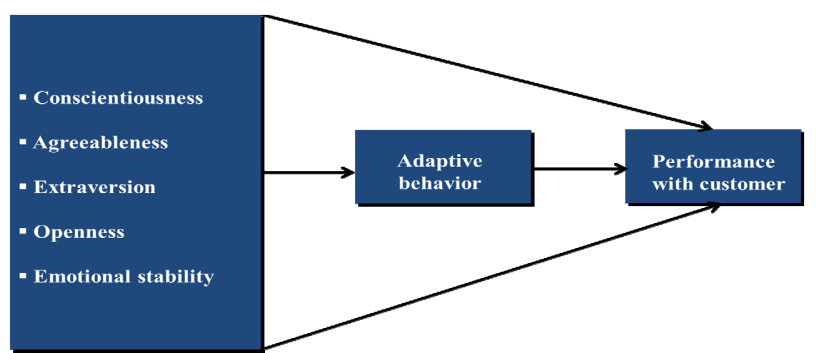

Figure 1. Research model.

with customers. Further, Five-Factor traits can also affect the employee's performance with customers indirectly. We elaborate on these linkages below.

\subsection{The Effects of Personality Traits on Performance with Customers}

There has been very little research that has directly examined the relationship between Five-Factor personality traits and performance in call centers. Sawyerr et al.'s (2009) call center research has shown, in contrast to the author's prediction, that only openness to experience was significantly correlated with employee performance. We think this result is attributable mainly to the performance criteria used. Sawyerr et al. [22] determined service employee performance to be measurable by three factors: 1) the accuracy of information provided to customers; 2) the speed of response to customer requests; and 3) the ability to solve problems. However, these items do not capture all aspects of employee performance with customers in call centers. For example, their performance criteria do not include the ability of employees to generate sales. This example shows how many authors [6,27] have highlighted the importance of choosing relevant performance criteria when investigating the relationship between personality traits and performance. In our research, we have chosen performance with customers as the criterion of employee performance in call centers, and we have justified the relevance of this choice below.

Many studies and meta-analyses have shown that conscientiousness and emotional stability are the most robust predictors of performance across all jobs and settings [3$6,11,28]$, specifically in jobs that require interaction [28]. Therefore, we predict that conscientiousness and emotional stability are correlated with performance with customers. In addition, based on Sawyerr et al.'s [28] results, we predict that openness to experience also has a positive effect on performance with customers.

Prior research (e.g., $[3-6,11,28]$ ) has highlighted the idea that the other five-factor personality traits (agreeableness and extraversion) are correlated with some performance criteria and some jobs [4]. In addition, Mount et al.'s [28] meta-analysis reported that Agreeableness and Extraversion are associated with performance in jobs that require interpersonal interaction. Bakker et al.'s [29] research also showed that Agreeableness is an important predictor of performance in cases of negative encounters between employees and customers. The cases described above cover two aspects of employee performance in call centers. Therefore, we expect that Agreeableness and Extraversion predict employee performance with customers in call centers. In sum, we expect the following:

$\boldsymbol{H}_{11}$. Conscientiousness will be positively associated with employee performance with customers in call centers.

$\boldsymbol{H}_{12}$. Agreeableness will be positively associated with employee performance with customers in call centers.

$\boldsymbol{H}_{13}$. Extroversion will be positively associated with employee performance with customers in call centers.

$\boldsymbol{H}_{14}$. Emotional stability will be positively associated with employee performance with customers in call centers.

$\boldsymbol{H}_{15}$. Openness to experience will be positively associated with employee performance with customers in call centers.

\subsection{The Effects of Personality Traits on Adaptive Behavior}

Headings, Very few researchers have investigated the relationship between personality traits and adaptive behavior. Spiro and Weitz [13] showed that five personality traits (self-monitoring, empathy, androgyny, being an opener, and locus of control) are positively associated with employee adaptiveness. Based on that study, Verbeke [30] investigated the impact of four personality traits (self-monitoring, interpersonal control, openness and rigidity). The results revealed that three personality traits (self-monitoring, interpersonal control and opening) are positively correlated with adaptive behavior, and, conversely, the results revealed that the personality trait of rigidity is negatively correlated with adaptive behavior. Studies also reported that Openness to Experience has a positive impact on adaptive performance [31] and on team adaptiveness [32]. Based on the above research, we expected the following:

$\boldsymbol{H}_{21}$. Openness to experience will be positively associated with employee adaptiveness in call centers.

To our knowledge, no prior research in general sales or in call centers has specifically addressed the relationship between the remaining four Five-Factor traits (Conscientiousness, Agreeableness, Extraversion and Emotional stability) and adaptive behavior.

People who score high on Conscientiousness seem to be hardworking, self-disciplined, task focused, and achievement oriented [33,34]. Prior studies have reported that this trait is associated with service orientation [35], and it is an important predictor of interpersonal interactions in service settings [28]. Recently, Brown and O'Donnell 
[36] showed that conscientiousness is a significant predictor of learning goal orientation, which in turn is recognized as a determinant of adaptiveness [37]. Guided by these studies, we expected the following:

$\boldsymbol{H}_{22}$. Conscientiousness will be positively associated with employee adaptiveness in call centers.

An individual who scores high in Agreeableness is friendly, cooperative, flexible, and has successful relationships with others [3,38]. Hogan et al. [35] have reported that Agreeableness is associated with service orientation. Mount et al.'s (1998) meta-analysis showed that Agreeableness is a determinant for positive interpersonal interactions in the workplace. In addition, Bonzionelos [39] indicates that agreeableness is related to the tendency to care for others. These qualities may be particularly relevant for employee who need to interact with each customer on a case-by-case basis. Therefore, we conclude the following:

$\boldsymbol{H}_{23}$. Agreeableness will be positively associated with employee adaptiveness in call centers.

Extroversion is characterized by sociability, activeness, energy, and assertiveness [17]. Onyemah (2008) [40] showed that extraversion can be linked to proactive behavior. Furthermore, some studies (e.g., [33,40,41]) have reported that extraversion is positively related to learning goal orientation. Finally, Judge et al. [42] highlighted that extraversion helps individuals to effectively communicate interpersonally. This disposition has the potential for increased success in adaptiveness selling. Based on these findings, we expect the following:

$\boldsymbol{H}_{24}$. Extroversion will be positively associated with employee adaptiveness in call centers.

Mount et al. [28] reported that people who score high in Emotional stability seem to have good interpersonal interactions in service settings and are able to fit their personalities to any particular context. Prior studies have also reported that Emotional stability is associated with service orientation [35]. Therefore, we expect the following:

$\boldsymbol{H}_{25}$. Emotional stability will be positively associated with employee adaptiveness in call centers.

In sum, in this study we expect the following:

$\boldsymbol{H}_{2}$. Five-Factor traits will be positively associated with employee adaptiveness in call centers.

\subsection{The Effects of Adaptive Behavior on Performance}

The impact of adaptive behavior on sales performance has been studied widely in sales literature. According to Weitz et al. [43], the adaptive selling framework and the practice of adaptive selling have a positive impact on employee performance. However, mixed results have emerged from empirical studies. Several salesforce researchers (e.g., $[13,14,44,45])$ have shown that adaptive be- haviors positively influence performance. However, a few authors (e.g., $[46,47])$ have found no relationship between adaptiveness and performance [44].

In this study, there are at least two reasons to conclude that employee adaptiveness in call centers will positively affect performance with customers. First, the qualitative call center research of Eveleth and Morris [15] highlighted the idea that many employees consider adaptive behavior to be critical for effectiveness in a call center environment. Second, Hunter and Perreault [25] showed that practicing adaptive behavior improves performance with customers. Therefore, we expect the following:

$\boldsymbol{H}_{3}$. Adaptive behavior will be positively associated with employee performance with customers in call centers.

\subsection{The Mediating Role of Adaptive Behavior}

Despite the many studies that have been conducted between personality traits and performance and between adaptive behavior and performance in both marketing literature and psychology, our knowledge about the relationship between those constructs in call centers is until recently quite limited. Based on the theorizing of the previous hypotheses, we expect that adaptive behavior mediates the relationship between Five-Factor traits and employee performance with customers at call centers. Specifically, we postulate that Conscientiousness, Agreeableness, Extraversion, Emotional Stability and Openness to Experience lead to greater employee adaptiveness in call centers, which in turn affect employee performance with customers. This mediating relationship is consistent with prior studies (e.g., $[3,4,6])$, which noted that mediating variables can explain uncounted variances between personality traits and performance. This mediating relationship is also consistent with recent developments in personality traits literature $[20,48]$. These studies suggest that a hierarchical model can better explain performance variability than a direct model between personality traits and employee performance. Therefore, we expect the following:

$\boldsymbol{H}_{4}$. Adaptive behavior will mediate the relationship between Five-Factor traits and employee performance with customers in call centers.

$\boldsymbol{H}_{41}$. Adaptive behavior will mediate the relationship between conscientiousness and employee performance with customers in call centers.

$\boldsymbol{H}_{42}$. Adaptive behavior will mediate the relationship between agreeableness and employee performance with customers in call centers.

$\boldsymbol{H}_{43}$. Adaptive behavior will mediate the relationship between extraversion and employee performance with customers in call centers.

$\boldsymbol{H}_{44}$. Adaptive behavior will mediate the relationship between emotional stability and employee performance 
with customers in call centers.

$\boldsymbol{H}_{45}$. Adaptive behavior will mediate the relationship between openness to experience and employee performance with customers in call centers.

\section{Research Design}

\subsection{Sample}

The Respondents were drawn from an important call center in New Brunswick, Canada. This call center addresses the principal Canadian internet and telephony organizations. A cover letter and questionnaire were sent to 200 employees. Completed questionnaires were received from 108 employees. Female respondents constituted $58.3 \%$ of the sample. $41.7 \%$ of respondents were young (less than 24 years old), and only $42.1 \%$ of employees held BAA degrees.

\subsection{Measures of Study Variables}

The questionnaire was developed by integrating questions used in previous researches. Table 1 summarizes the scale items. The scale for performance with customers comprises five items developed by Hunter and Perreault [25]. The Five-Factor traits (Conscientiousness, Agreeableness, Extraversion, Emotional Stability and Openness to Experience) were measured using 16 items used by Sawyerr et al. [22] and developed by Goldberg [49]. Finally, adaptive behavior was determined based upon the four items used by Hunter and Perreault [25] and developed by Spiro and Weitz [13].

\subsection{Analysis Strategy}

In this study, the method of structural equations is adopted as an analysis strategy, as recommended by Roussel et al. [50] for numerous assumed relations between variables. In the literature, there are primarily two types of statistical approaches based on structural equations: Linear Structural Relationships ("LSR") and Partial Least Squares ("PLS"). In this research, we adopted the PLS approach for three reasons. First, the size of our sample is insufficient to render an adequate analysis by the Lisrel approach. Second, the PLS approach tolerates non-normality and especially multicollinearity [51]. Finally, beta PLS path coefficient estimation is more accurate than the Lisrel approach [51].

To test mediation, this study followed the procedures suggested by Baron and Kenny [52]. This method involves establishing four equations of regression that link up three types of variables. The first regression determines whether the independent variable has a direct effect on the dependent variable. The second regression examines whether the independent variable has a hitting action on the mediating variable. The third regression analyzes whether the mediating variable has an impact on the dependent variable. Finally, the last regression examines whether the influence of the independent variables on the dependent variable is considerably reduced when the mediating variable is added. In this respect, the test of Sobel will be used to prove if the reduction of the effect of independent variables in the dependent variable in the presence of the mediator variable is significant. This test involves calculating the $\mathrm{z}$ value $\left(\mathrm{z}=(\mathrm{a} * \mathrm{~b}) / \sqrt{ }\left(\mathrm{b}^{2} *\right.\right.$ $\left.\mathrm{s}_{\mathrm{a}}{ }^{2}+\mathrm{a}^{2} * \mathrm{~s}_{\mathrm{b}}{ }^{2}\right)$; a and $\mathrm{b}$ : designed the non-standardized regression coefficients due respectively to the effect of the independent variable on the mediating variable and the effect of the mediating variable on the dependent variable; $\mathrm{s}_{\mathrm{a}}$ and $\mathrm{s}_{\mathrm{b}}$ : standard errors of $\mathrm{a}$ and $\mathrm{b}$ ).

\section{Results}

\subsection{Measure Validation}

As recommended by Anderson and Gerbing [53], we developed a measurement model before estimating the structural paths to test the hypothesized relationships between constructs. Unidimensionality was assessed prior to examining reliability and validity [54]. To assess the unidimensionality of the constructs, all independent and dependent variables were analyzed by using varimax rotation, taking three criteria into consideration: 1) all items having a lower community under 0.4 will be eliminated; 2) the factors extracted are those that have a value higher than 1; and 3) Cronbach's exceeded the minimum acceptable values, which was 0.7 . The results illustrate that all constructs are unidimensional. As Table 1 reports, all items had a significant loading on corresponding constructs because the lowest $\lambda$ was $0.71(>0.7)$ and the lowest t-value was 6.53 (>1.96). Using Chin's [51] criteria, the convergent validity of the constructs is acceptable. All composite reliabilities, ranging from 0.90 to 0.93 , are also above the cut-off value of 0.70 , and the extracted variances [55] were higher than 0.5 . Therefore, reliability is also acceptable.

The study then assessed the discriminant validity of the key constructs by using the procedures recommended by Fornell and Larker [55]. It consisted of checking whether the square roots of the AVE values were consistently greater than all corresponding correlations as shown in Table 2. As reported in Table 2, the analysis showed that each construct shares more variance with its corresponding measures than it shares with other constructs in the model. Therefore, all constructs reveal an acceptable discriminant validity.

\subsection{Structural Model}

The hypotheses were tested by simultaneously testing the proposed relationships using Partial Least Squares (PLS) path modelling. PLS is a prediction-oriented, variance-based 
Table 1. Survey items, reliability and validity for measures in the study.

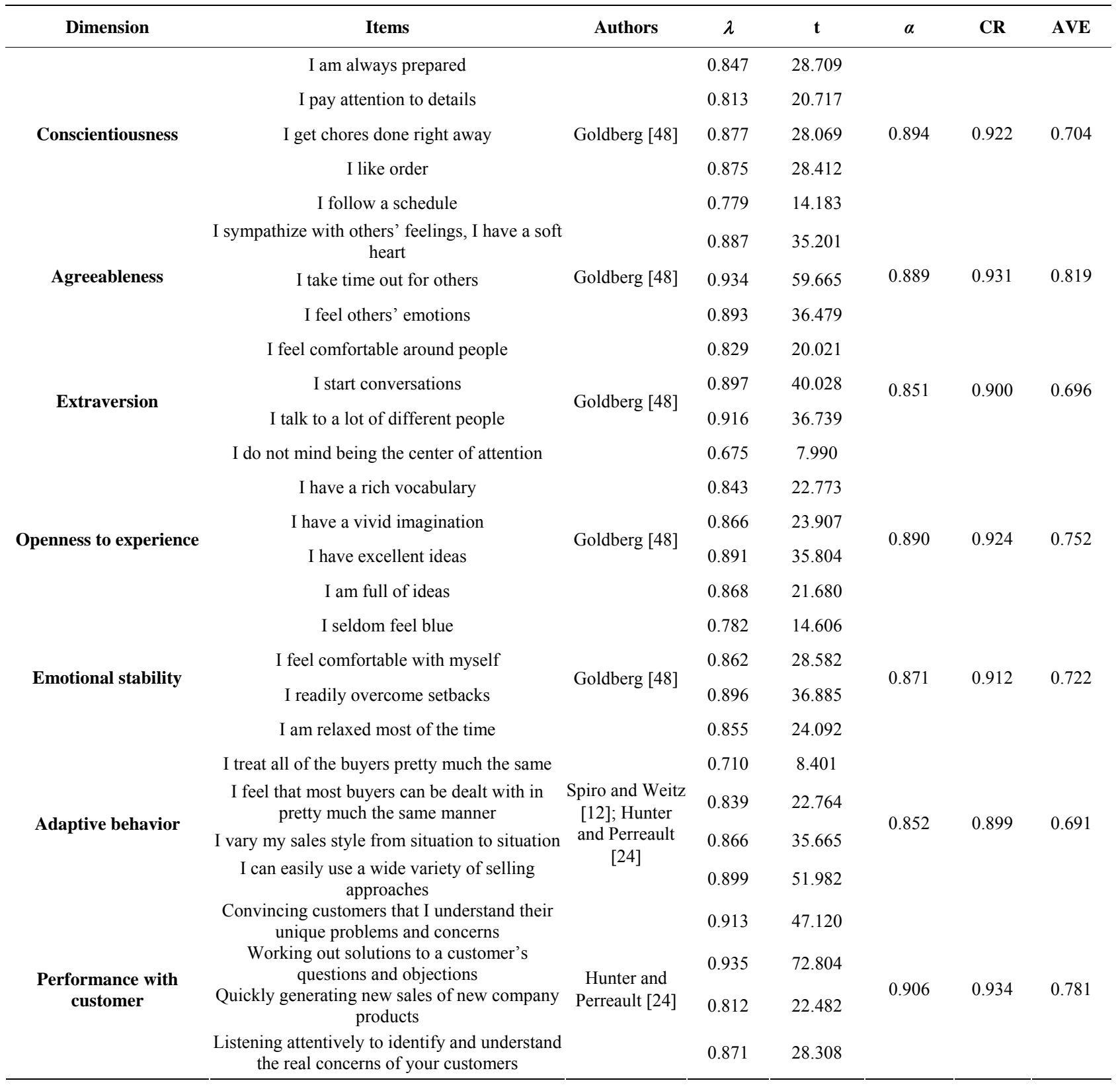

Table 2. Discriminant validity.

\begin{tabular}{cccccccc}
\hline & $\mathbf{1}$ & $\mathbf{2}$ & $\mathbf{3}$ & $\mathbf{4}$ & $\mathbf{5}$ & $\mathbf{6}$ & $\mathbf{8}$ \\
\hline Agreeableness & 1.000 & & & & & & \\
Adaptive behavior & 0.549 & $\mathbf{( 0 . 9 0 5 )}$ & & & & \\
Conscientiousness & 0.750 & 0.558 & $\mathbf{( 0 . 8 3 9 )}$ & & & \\
Emotional stability & 0.702 & 0.503 & 0.656 & $\mathbf{( 0 . 8 5 0 )}$ & & \\
Extraversion & 0.534 & 0.433 & 0.589 & 0.574 & $\mathbf{( 0 . 8 3 4 )}$ & & \\
$\begin{array}{c}\text { Openness to } \\
\text { experience }\end{array}$ & 0.262 & 0.296 & 0.354 & 0.352 & 0.550 & $\mathbf{( 0 . 8 6 7 )}$ & \\
$\begin{array}{c}\text { Performance with } \\
\text { customer }\end{array}$ & 0.609 & 0.828 & 0.622 & 0.567 & 0.533 & $0.416 \mathbf{( 0 . 8 8 3 )}$ \\
\hline
\end{tabular}

Diagonal entries show the square roots of average variance extracted, others represent correlation coefficients. approach to Structural Equation Modelling (SEM), which makes very few assumptions about the distribution of the variables, and requires relatively few observations, compared to more traditional Maximum Likelihood (ML) SEM techniques such as LISREL. PLS has been chosen over LISREL because PLS is highly appropriate for complexes predictive models [52]. Furthermore, our sample size $(\mathrm{N}=108)$ is small, then it is inadequate for LISREL analysis.

We used specifically SmartPLS, to estimate both the main and mediation effects stated in the hypotheses shown in Figure 1. The results are reported in Table 3. 
Table 3. Main and mediating effects.

\begin{tabular}{|c|c|c|c|}
\hline & Model 1 & & odel 2 \\
\hline $\begin{array}{l}\text { Independents } \\
\text { variables }\end{array}$ & $\begin{array}{l}\text { Performance } \\
\text { with customer }\end{array}$ & $\begin{array}{l}\text { Adaptive } \\
\text { behavior }\end{array}$ & $\begin{array}{c}\text { Performance } \\
\text { with customer }\end{array}$ \\
\hline Conscientiousness & $\begin{array}{l}0.24^{* *} \\
(3.16)\end{array}$ & $\begin{array}{l}0.25^{* *} \\
(3.36)\end{array}$ & $\begin{array}{c}0.08 \\
(1.53)\end{array}$ \\
\hline Agreeableness & $\begin{array}{l}0.25^{* *} \\
(3.67)\end{array}$ & $\begin{array}{l}0.21^{* *} \\
(2.74)\end{array}$ & $\begin{array}{l}0.10^{* *} \\
(2.11)\end{array}$ \\
\hline Extraversion & $\begin{array}{c}0.10^{*} \\
(1.89)\end{array}$ & $\begin{array}{c}0.06 \\
(0.96)\end{array}$ & - \\
\hline Emotional stability & $\begin{array}{l}0.12^{* *} \\
(2.06)\end{array}$ & $\begin{array}{l}0.13^{* *} \\
(1.98)\end{array}$ & $\begin{array}{c}0.04 \\
(0.77)\end{array}$ \\
\hline Openness to experience & $\begin{array}{l}0.17^{* *} \\
(3.39)\end{array}$ & $\begin{array}{c}0.07 \\
(1.14)\end{array}$ & - \\
\hline Adaptive behavior & - & & $\begin{array}{c}0.64^{* *} \\
(15.51)\end{array}$ \\
\hline $\mathbf{R}^{2}$ & 0.49 & - & 0.75 \\
\hline
\end{tabular}

${ }^{* *} \mathrm{p}<0.05,{ }^{*} \mathrm{p}<0.1$.

\subsubsection{The Effects of Personality Traits on Performance with Customers}

Hypothesis 1 posits that each Five-Factor trait positively affects employee performance with customers. The results reported in Table $\mathbf{3}$ show that Conscientiousness, Agreeableness, Extraversion, Emotional, Stability and Openness to Experience are significantly positively related to performance with customers $\left(\beta_{11}=0.24 ; \mathrm{t}=3.16\right.$, $\mathrm{p}<0.5),\left(\beta_{12}=0.25 ; \mathrm{t}=3.27, \mathrm{p}<0.5\right),\left(\beta_{13}=0.10 ; \mathrm{t}=\right.$ $1.89, \mathrm{p}<0.1),\left(\beta_{14}=0.12 ; \mathrm{t}=2.06, \mathrm{p}<0.5\right)$ and $\left(\beta_{15}=\right.$ $0.17 ; \mathrm{t}=3.39, \mathrm{p}<0.5)$, supporting $H_{11}, H_{12}, H_{13}, H_{14}$ and $H_{15}$. We suspect that the lowest t-value of $H_{13}$ is due only to the size of our sample (only 108 respondents). Therefore, as expected, the Five-Factor traits predict employee performance with customers in call centers. This result is consistent with previous research (e.g., [3-6,11,27]. However, these findings run contrary to Sawyerr et al.'s [22] call center research, which indicated that only openness to experience was significantly correlated with employee performance.

With respect to t-value, Table 3 reported also that Agreeableness is the biggest predictor of performance with customers, followed by Openness to experience, Conscientiousness, Emotional stability and Extraversion, respectively.

\subsubsection{The Effects of Personality Traits on Adaptive Behavior}

We hypothesized that in call centers each Five-Factor trait has a positive influence on adaptive behavior. As reported in Table 3, Conscientiousness, Agreeableness and Emotional stability positively effect adaptive behavior in call centers $\left(\beta_{21}=0.25 ; \mathrm{t}=3.36, \mathrm{p}<0.5\right),\left(\beta_{22}=\right.$ $0.21 ; \mathrm{t}=2.74, \mathrm{p}<0.5)$ and $\left(\beta_{24}=0.13 ; \mathrm{t}=1.98, \mathrm{p}<0.1\right)$, supporting $H_{21}, H_{22}$ and $H_{24}$. However, Table 3 shows that, contrary to our predictions, we found no significant associations between Extraversion and Openness to experience and adaptive behavior $\left(\beta_{23}=0.06 ; \mathrm{t}=0.96, \mathrm{p}>\right.$ $0.1)$ and $\left(\beta_{25}=0.07 ; \mathrm{t}=1.14, \mathrm{p}>0.1\right)$. Thus, our results do not support $H_{23}$ and $H_{25}$. Accordingly, $H_{2}$ is partially accepted.

\subsubsection{The Effects of Adaptive Behavior on Performance with Customers}

As predicted, adaptive behavior has a significant impact on employee performance with customers in a call center environment $\left(\beta_{3}=0.64 ; \mathrm{t}=15.51, \mathrm{p}<0.5\right)$, supporting $H_{3}$. This result is consistent with previous empirical research (e.g., $[13,14,44])$. This result also confirms Eveleth and Morris [15] qualitative call center research.

\subsubsection{The Mediating Role of Adaptive Behavior}

As previously shown, all Five-Factor traits influence performance with customers, while only three traits (Conscientiousness, Agreeableness and Emotional stability) have a positive effect on adaptive behavior selling, which in turn influences employee performance with customers. Therefore, our results do not support $H_{43}$ and $H_{45}$.

To test the mediating role of adaptive behavior between these three traits (Conscientiousness, Agreeableness and Emotional stability) and performance with customers, two structural equation models (Model 1 and Model 2), which used SmartPLS, were developed and compared. Model 1 stressed that Y (performance with customer) is influenced only by $\mathrm{X}$ (personality traits), Model 1: X $\rightarrow$ Y. Model 2 described a scenario whereby these traits influenced only employee performance with customers through adaptive behavior (M), Model 2: $\mathrm{X} \rightarrow$ $\mathrm{M} \rightarrow \mathrm{Y}$. A comparison of Models 1 and 2 shows that the positive impact of Conscientiousness and Emotional stability on performance with customers in Model 1 becomes insignificant in Model $2\left(\beta_{11}=0.24 ; \mathrm{t}=3.16\right.$ in Model 1 become $\beta_{11}=0.08 ; \mathrm{t}=1.53$ in Model 2 ; and $\beta_{12}=$ $0.25 ; \mathrm{t}=2.06$ in Model 1 become $\beta_{12}=0.04 ; \mathrm{t}=0.77$ in Model 2). Therefore, adaptive behavior mediates the relationship between two traits (Conscientiousness and Emotional stability) and employee performance with customers at call centers. Accordingly, $H_{41}$ and $H_{44}$ are supported. In addition, the comparison of Models 1 and 2 indicates that the direct impact of Agreeableness on performance with customers (Model 1) was also significant when a mediating variable (adaptive behavior) was incorporated (Model 2). However, this impact becomes weaker from Model 1 to Model $2\left(\beta_{12}=0.25\right.$ in Model 1 versus $\beta_{12}=0.10$ in Model 2 ). The Sobel test also shows that this reduction is significant $(\mathrm{z}$-score $=3.34, \mathrm{p}<0.05)$. Therefore, adaptive behavior partially mediates the relationship between Agreeableness and employee performance with customers in call centers, supporting $H_{42}$. In sum, our results partially support $H_{4}$. 
As reported by Table 3, the $\Delta \mathrm{R}^{2}$ between Model 1 and 2 is important $(26 \%=75 \%-45 \%)$. The difference is statistically significant $\left(\mathrm{F}_{\text {Model 1-2 }}=16.64>\mathrm{F}_{\text {Critical }}=3.94\right)$. Therefore, the incorporation of adaptive behavior in Model 2 reduces the uncounted variance between personality traits and performance.

\section{Discussion}

To our knowledge, no prior call center research has specifically addressed the relationship between the four Five-Factor (Conscientiousness, Agreeableness, Extraversion and Emotional stability), adaptive behavior and employee performance. Therefore, this study adds to research efforts to understand the relationship between these constructs in call centers.

Many authors (e.g., [3-6,8,11,12]) have highlighted the idea that that personality traits, specifically Five-Factor traits, are good predictors of performance in a selling context. However, Sawyerr et al.'s [22] call center studies have shown, in contrast to the author's prediction, that only openness to experience was negatively correlated with employee performance. Therefore, the first objective of this study is to replicate the relationship between these constructs. Instead of the service performance criteria used by Sawyerr et al. [22], we employed performance with customers because it serves as an effective indicator of employee performance in call centers. The results of this study support the positive relationship of all Five-Factor traits and employee performance with customers in call centers. These results are highly consistent with findings in the extant literature. We think the Sawyerr et al. [22] result is primarily attributable to the performance criteria used.

Adaptive behavior is an important driver of employee performance in face-to-face interactions [14]. Surprisingly, despite the fast growth of the call center industry, very few studies have analyzed adaptive behavior in call centers. Recently, the qualitative call center research of Eveleth and Morris [15] reported that employee highlight the importance of adaptive behavior in phone interactions. The second aim of this study was to assess this proposition empirically by examining the relationship between adaptive behavior and employee performance with customers. Our results showed a strong positive impact of adaptive behavior on performance with customers. Thus, this study confirms the exploratory findings of Eveleth and Morris [15].

Personality traits are a critical factor of employee performance. Many call centers, especially in Canada, take personality traits into account in the hiring process. Researchers have found that when selective hiring methods are used, there is less employee turnover, and training efforts are more effective [56]. Employee turnover in call centers in Canada is approximately 29\%. Therefore, hir- ing employees with the right personality traits is critical for Canadian call centers to maintain a competitive advantage. Surprisingly, very few authors have investigated the link between the Five-Factor traits and adaptive behavior. To our knowledge, only four studies [13,30-32] have analyzed the impact of openness to experience on adaptive behavior, but not in a call center environment. Therefore, the third goal of this study is to investigate the relationship between Five-Factor traits and adaptive behavior in call centers. Our results show that three of the Five-Factor traits are associated with adaptive behavior. Specifically, Conscientiousness, Agreeableness and Emotional stability positively affect adaptive behavior in call centers, while we found no significant associations between Extraversion and Openness to experience and adaptive behavior. The findings in our analysis of the relationship between openness to experience and adaptive behavior do not comport with previous finding [13, 30-32]. We believe the difference in findings is due to the small size of our sample. Indeed, the t-value between the constructs in our study is 1.14 , and therefore we presume if our size were to exceed 200 respondents, this t-value would become higher than the critical value (1.96).

Many researchers (e.g., [8,9,11]) call for further investigation on the indirect relationship, via moderators or mediating variables, between personality traits and employee performance. Consistent with this line of research, our last goal was to investigate whether adaptive behavior mediates the relationship between Five-Factor traits and performance with customers. Our results show that adaptive behavior mediates the relationship between three traits (Conscientiousness, Agreeableness and Emotional stability) and employee performance with customers at call centers. In addition, our results indicate that the model incorporating adaptive behavior between FiveFactor traits and performance with customers shows 26\% more employee performance with customers variability than the direct model. This finding reinforces the recommendations of previous literature (e.g., [20,48]) that the hierarchical model between personality traits and employee performance can better explain performance variability than the direct model. Indeed, Adaptive behavior can be considered to be a surface trait, and FiveFactor can be considered to be an elemental trait.

\section{Managerial Implications}

The results of this research allow us to address many managerial implications. First, our research confirms the validity of the Five-Factor traits as a hiring tool in the staffing of call centers. Indeed, our study shows that Five-Factor traits account for $47 \%$ of employee performance with customers at call centers. This study also reported that Agreeableness is the biggest predictor of 
performance with customers, followed by Openness to experience, Conscientiousness, Emotional stability and Extraversion, respectively. Therefore, call center sales managers have to take these traits into account in the process of employee selection. Second, our study confirms the critical role of adaptive behavior for employee performance in call centers. Therefore, sales managers should encourage employee to be more adaptive and able to evaluate customers to better satisfy them. Along these lines, this study finds that the three traits (Conscientiousness, Agreeableness and Emotional stability) are positively associated with adaptive behavior. Conscientiousness was the biggest predictor of employee adaptive behavior, followed by Agreeableness and Emotional stability, respectively. Therefore, it appears that two traits are very important for employee performance in call centers. These traits are Conscientiousness and Agreeableness because there are strongly associated with selling adaptiveness and performance with customers. For call center sales managers, this result is significant because understanding key traits can improve hiring procedures and in turn can increase call center performance as well as reduce employee turnover.

\section{Limitations and Future Research}

Although the results obtained provide general support for the proposed theoretical framework, a few potential limitations of this study should be noted. First, the sample size of respondents is not sufficient. Second, the generalization of this study may be a limiting factor because the research sample was drawn from only one call center in Canada. Finally, we have used only one hierarchical level to describe the relationship between personality traits and performance. Mowen and Spears [20] have recommended three levels, and Mowen [19] recommended four levels.

To enhance external validity, future research efforts should obtain a representative sample from more call centers. Other personality dimensions (e.g., Locus of control, rigidity) and other performance criteria should be used to better assess the relationship between personality traits and performance. Finally, it is better to use four hierarchical models (3M) as suggested by Mowen [18] to further understand the relationship between personality traits and performance. In this hierarchical model, adaptive behavior can be considered to be a surface trait and personality traits can be considered to be elemental. Further, other variables can be integrated into our model, such as compound traits and situational traits.

\section{REFERENCES}

[1] B. Schneider and D. E. Bowen, "Employee and Customer Perceptions of Service in Banks: Replication and Extension," Journal of Applied Psychology, Vol. 70, No. 3,
1985, pp. 423-433.

[2] D. J. Cran, "Towards Validation of the Service Orientation Construct," Service Industries Journal, Vol. 14, No. 1, 1994, pp. 34-44.

[3] M. R. Barrick and M. K. Mount, "The Big Five Personality Dimensions and Job Performance: A Meta-Analysis," Personnel Psychology, Vol. 44, No. 1, 1991, pp. 1-26.

[4] G. M. Hurtz and J. J. Donovan, "Personality and Job Performance: The Big Five Revisited," Journal of Applied Psychology, Vol. 85, No. 6, 2000, pp. 869-879.

[5] J. F. Salgado, "Personnel Selection Methods," In: C. L. Cooper and I. T. Robertson, Eds., International Review of Industrial and Organizational Psychology, Wiley, Chichester, 1999, pp. 1-54.

[6] M. R. Barrick, M. K. Mount and T. A. Judge, "Personality and Performance at the Beginning of the New Millennium: What Do We Know and Where Do We Go Next?" Personality and Performance, Vol. 9, No. 1-2, 2001, pp. 9-30.

[7] G. A. Churchill Jr., N. M. Ford, S. W. Hartley and O. C. Walker Jr., "The Determinants of Salespersons Performance: Meta-Analysis," Journal of Marketing Research, Vol. 22, 1985, pp. 103-118.

[8] P. T. Costa and R. R. McCrae, "Neo-Pi Professional Manual," Psychological Assessment Resources, Odessa, 1989.

[9] M. R. Barrick, T. R. Mitchell and G. L. Stewart, "Situational and Motivational Influences on Trait-Behavior Relationships," In: M. Barrick and Ryanam, Eds., Personality and Work: Reconsidering the Role of Personality in Organizations, Jossey-Bass, San Francisco, 2003, pp. 60-82.

[10] L. M. Hough, "Emerging Trends and Needs in Personality Research and Practice: Beyond Main Effects," In: M. Barrick and Ryanam, Eds., Personality and Work: Reconsidering the Role of Personality in Organizations, Jossey-Bass, San Francisco, 2003, pp. 285-325.

[11] T. A. Judge and A. L. Kristof-Brown, "Personality, Interactional Psychology, and Person-Organization Fit," In: B. Schneider and D. B. Smith, Eds., Personality and Organizations, Lawrence Erlbaum Associates, Mahwah, 2003, pp. 126-161.

[12] M. R. Barrick, L. Parks and M. K. Mount, "Self-Monitoring as a Moderator of the Relationship between Personality Traits and Performance," Personnel Psychology, Vol. 58, No. 3, 2005, pp. 745-767.

[13] R. L. Spiro and B. A. Weitz, "Adaptive Selling: Conceptualization, Measurement, and Nomological Validity," Journal of Marketing Research, Vol. 27, No. 1, 1990, pp. 61-69.

[14] H. Sujan, B. A. Weitz and N. Kumar, "Learning Orientation, Working Smart, and Effective Selling," Journal of Marketing, Vol. 58, No. 3, 1994, pp. 39-52.

[15] D. M. Eveleth and L. Morris, "Adaptive Selling in a Call Center Environment: A Qualitative Investigation," Journal of Interactive Marketing, Vol. 16, No. 1, 2002, pp. 25-39.

[16] P. T. Costa and R. R. McCrae, "NEO-PI Professional Manual," Psychological Assessment Resources, Odessa, 
1989.

[17] P. T. Costa and R. R. McCrae, "Revised NEO Personality Inventory and Five-Factor Model Inventory Professional Manual," Psychological Assessment Resources, Odessa, 1992.

[18] A. E. Poropat, "A Meta-Analysis of the Five-Factor Model of Personality and Academic Performance," Psychological Bulletin, Vol. 135, No. 2, 2009, pp. 322-338.

[19] M. K. Mount, A. Witt and M. R. Barrick, "Incremental Validity of Empirically-Keyed Biographical Scales over GMA and the Big Five Personality Constructs," Personnel Psychology, Vol. 53, No. 2, 2000, pp. 299-323.

[20] J. C. Mowen and N. Spears, "A Hierarchical Model Approach to Understanding Compulsive Buying among College Students," Journal of Consumer Psychology, Vol. 8, No. 4, 1999, pp. 407-430.

[21] E. G. Harris and J. C. Mowen, "The Influence of Cardinal-, Central-, and Surface-Level Personality Traits on Consumers' Bargaining and Complaint Intentions," Psychology and Marketing, Vol. 18, No. 18, 2001, pp. 11551185.

[22] O. O. Sawyerr, S. Srinivas and S. Wang, "Call Center Employee Personality Factors and Service Performance," Journal of Services Marketing, Vol. 23, No. 5, 2009, pp. 301-317. doi:10.1108/08876040910973413

[23] M. D. Hartline and O. C. Ferrell, "The Management of Customer-Contact Service Employees: An Empirical Investigation," Journal of Marketing, Vol. 60, No. 4, 1996, pp. 52-70. doi:10.2307/1251901

[24] M. W. Johnston and G. W. Marshall, "Churchill/Ford/ Walker's Sales Force Management," McGraw-Hill/Irwin, New York, 2006.

[25] G. K. Hunter and W. D. Perreault, "Sales Technology Orientation, Information Effectiveness, and Sales Performance," Journal of Personal Selling and Sales Management, Vol. 26, No. 2, 2006, pp. 95-113. doi:10.2753/PSS0885-3134260201

[26] G. K. Hunter and W. D. Perreault, "Making Sales Technology Effective," Journal of Marketing, Vol. 71, No. 1, 2007, pp. 16-34. doi:10.1509/jmkg.71.1.16

[27] J. Hogan and B. Holland, "Using Theory to Evaluate Personality and Job-Performance Relations: A Socioanalytic Perspective," Journal of Applied Psychology, Vol. 88 , No. 1, 2003, pp. 100-112. doi:10.1037/0021-9010.88.1.100

[28] M. K. Mount, M. R. Barrick and G. L. Stewart, "FiveFactor Model of Personality and Performance in Jobs Involving Interpersonal Interactions," Human Performance, Vol. 11, No. 2-3, 1998, pp. 145-165.

[29] A. B. Bakker, K. I. van der Zee, K. A. Lewig and M. F. Dollard, "The Relationship between the Big Five Personality Factors and Burnout: A Study among Volunteer Counselors," Journal of Social Psychology, Vol. 146, No. 1, 2006, pp. 31-50. doi:10.3200/SOCP.146.1.31-50

[30] W. Verbeke, "Personality Characteristics That Predict Effective Performance of Sales People," Scandinavian Journal of Management, Vol. 10, No. 1, 1994, pp. 49-57. doi:10.1016/0956-5221(94)90036-1
[31] E. D. Pulakos, N. Schmitt, D. W. Dorsey, S. Arad, J. W. Hedge and W. Borman, "Predicting Adaptive Performance: Further Tests of a Model of Adaptability," Human Performance, Vol. 15, No. 4, 2002, pp. 299-323. doi:10.1207/S15327043HUP1504 01

[32] J. A. LePine, "Team Adaptation and Postchange Performance: Effects of Team Composition in Terms of Members' Cognitive Ability and Personality," Journal of Applied Psychology, Vol. 88, No. 1, 2003, pp. 27-39. doi:10.1037/0021-9010.88.1.27

[33] R. R. McCrae and O. John, "An Introduction to the Five-Factor Model and Its Applications," Journal of Personality, Vol. 60, No. 2, 1992, pp. 174-214. doi:10.1111/j.1467-6494.1992.tb00970.x

[34] D. Zweig and J. Webster, "What Are We Measuring? An Examination of the Relationships between the Big-Five Personality Traits, Goal Orientation and Performance Intentions," Personality and Individual Differences, Vol. 36, No. 7, 2004, pp. 1693-1708. doi:10.1016/j.paid.2003.07.010

[35] J. Hogan, R. Hogan and C. M. Busch, "How to Measure Service Orientation," Journal of Applied Psychology, Vol. 69, No. 1, 1984, pp. 167-173. doi:10.1037/0021-9010.69.1.167

[36] S. Brown and O. D. Edward, "Proactive Personality and Goal Orientation: A Model of Directed Effort Journal of Organizational Culture," Communications and Conflict, Vol. 15, No. 1, 2011, pp. 103-120.

[37] M. Ahearne, S. K. Lam, J. E. Mathieu and W. Bolander, "Why Are Some Salespeople Better at Adapting to Organizational Change?" Journal of Marketing, Vol. 74, No. 3, 2010, pp. 65-79. doi:10.1509/jmkg.74.3.65

[38] R. R. McCrae and P. T. Costa, "Adding Liebe Und Arbeit: The Full Five-Factor Model and Well-Being," Personality and Social Psychology Bulletin, Vol. 17, No. 2, 1991, pp. 227-232. doi:10.1177/014616729101700217

[39] N. Bonzionelos, "The Big Five of Personality and Work Involvement," Journal of Managerial Psychology, Vol. 19, No. 10, 2003, pp. 69-81.

[40] V. Onyemah, "From Sales Force Control Systems to Sales Manager Development: A Sequence of Studies," Presentation at Erin Anderson Research Conference, Philadelphia, 2008, pp. 17-19.

[41] A. J. Elliot and T. M. Thrash, “Approach-Avoidance Motivation in Personality: Approach and Avoidance Temperaments and Goals," Journal of Personality and Social Psychology, Vol. 82, No. 5, 2002, pp. 804-818. doi:10.1037/0022-3514.82.5.804

[42] T. A. Judge, C. L. Jackson, J. C. Shaw, B. A. Scott and R. L. Rich, "Self-Efficacy and Work-Related Performance: The Integral Role of Individual Differences," Journal of Applied Psychology, Vol. 92, No. 1, 2007, pp. 107-127. doi:10.1037/0021-9010.92.1.107

[43] B. A. Weitz, H. Sujan and M. Sujan, "Knowledge Motivation, and Adaptive Behavior: A Framework for Improving Selling Effectiveness," Journal of Marketing, Vol. 50, No. 2, 1986, pp. 174-191. doi:10.2307/1251294

[44] J. E. Park and G. D. Deitz, "The Effect of Working Rela- 
tionship Quality on Salesperson Performance and Job Satisfaction: Adaptive Selling Behavior in Korean Automobile Sales Representatives," Journal of Business Research, Vol. 59, No. 2, 2006. pp. 204-213. doi:10.1016/i.jbusres.2005.04.002

[45] J. E. Park, J. Kim, A. J. Dubinsky and H. Lee, "How Does Sales Force Automation Influence Relationship Quality and Performance? The Mediating Roles of Learning and Selling Behaviours," Industrial Marketing Management, Vol. 39, No. 7, 2010, 1128-1138. doi:10.1016/j.indmarman.2009.11.003

[46] J. R. Goolsby, R. R. Lagace and M. L. Boorom, "Psychological Adaptiveness and Sales Performance," Journal of Personal Selling and Sales Management, Vol. 12, No. 2, 1992, pp. 51-66.

[47] RéC. McMurrian, "A Social Cognitive Theory Model of Salesperson Performance," Dissertation, The Louisiana State University, Baton Rouge, 1996.

[48] J. Mowen, "The 3M Model of Motivation and Personality,” Kluwer Academic Press, Norwell, 2000.

[49] L. R. Goldberg, "A Broad-Bandwidth, Public Domain, Personality Inventory Measuring the Lower-Level Facets of Several Five-Factor Models," In: I. Mervielde, I. Deary, F. De Fruyt and F. Ostendorf, Eds., Personality Psychology in Europe, Tilburg University Press, Tilburg, 1999, pp. 7-28.

[50] P. Roussel, F. Durrieu, E. Campoy and A. El Akremi,
“Méthodes D’équations Structurelles: Recherches et Application en Gestion," Economica, Paris, 2002.

[51] W. W. Chin, "The Partial Least Squares Approach for Structural Equation Modeling," In: G. A. Marcoulides, Ed., Modern Methods for Business Research, Lawrence Erlbaum Associates, Hillsdale, Lawrence Erlbaum Associates, Mahwah, 1998, pp. 295-336.

[52] R. M. Baron and D. A. Kenny, "The Moderator-Mediator Variable Distinction in Social Psychological Research: Conceptual, Strategic and Statistical Considerations," Journal of Personality and Social Psychology, Vol. 51, No. 6, 1986, pp. 1173-1182. doi:10.1037/0022-3514.51.6.1173

[53] J. C. Anderson and D. W. Gerbing, "Structural Equation Modeling in Practice: A Review and Recommended TwoStep Approach," Psychological Bulletin, Vol. 103, No. 3, 1988, pp. 411-423. doi:10.1037/0033-2909.103.3.411

[54] J. F. Hair Jr., R. E. Anderson, R. L. Tatham and W. C. Black, "Multivariate Data Analysis with Readings," 4th Edition, Prentice Hall Inc., Upper Saddle River, 1995.

[55] C. Fornell and D. F. Larcker, "Evaluating Structural Equation Models with Unobservable Variables and Measurement Error," Journal of Marketing Research, Vol. 18, No. 1, 1981, pp. 39-50. doi:10.2307/3151312

[56] F. F. Reichheld and W. E. Sasser, "Zero Defections: Quality Comes to Services," Harvard Business Review, Vol. 68, No. 5, 1990, pp. 105-111. 